\title{
Synthetic Ligands for apo-Neocarzinostatin
}

Stephen Caddick, ${ }^{a *}$ Frederick W. Muskett, ${ }^{\mathrm{b}}$ Rhys G. Stoneman, ${ }^{\mathrm{c}}$ Derek N. Woolfson $^{d}$

a. Department of Chemistry, University College London, 20 Gordon Street, London, WC1H OAJ, UK

b. Biological NMR Centre, Department of Biochemistry, Henry Wellcome Building, University of Leicester, University_Rd., Leicester LE1 9HN, UK

c. Department of Biochemistry, School of Life Sciences, University of Sussex, Brighton, BN1 $9 Q G$

d. School of Chemistry, University of Bristol, Cantock's Close, Bristol, BS8 1TS; and

Department of Biochemistry, School of Medical Sciences, University Walk, Bristol BS8 1TD.

s.caddick@ucl.ac.uk

\section{Supporting Information}


Figure1. Molecular structures of ligands discussed and / or referred to in text.
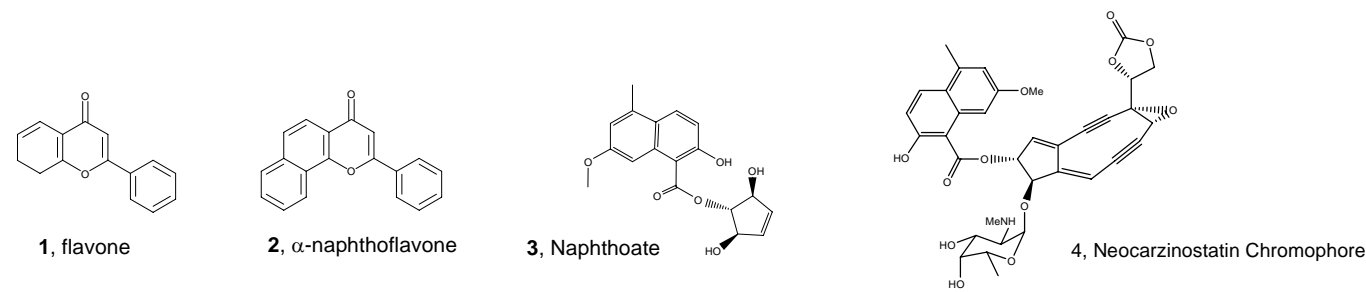

For structure determination of natural holocomplex see: Kim, K.H.; Kwon, B.M.; Myers, A.G.; Rees, D.C. Crystal structure of neocarzinostatin, an antitumor protein-chromophore complex. Science 1993, 262, 1042. PDB accession code: $1 \mathrm{NCO}$.

For structure determination of complex of 3 with apoNCS see: Urbaniak, M. D.; Muskett, F.W.; Finucane, M. D.; Caddick, S.; Woolfson, D. N.; Solution Structure of a Novel Chromoprotein Derived from Apo-Neocarzinostatin and a Synthetic Chromophore, Biochemistry, 2002, 41, 11731 PDB accession code 1J5I. 
Figure 2: Representative examples of ligands which failed to bind apoNCS when evaluated using HSQC and $/$ or fluorescence experiments.<smiles>O=C(O[C@H]1C=C(Br)C(=O)[C@@H]1O)c1c(O)ccc2ccccc12</smiles><smiles>COc1cc(C)c2ccc(O)c(C(=O)O[C@H]3C=C[C@H](O)[C@H]3O)c2c1</smiles><smiles>O=C(O[C@H]1C(=O)C=C[C@@H]1O)c1c(O)ccc2ccccc12</smiles><smiles>O=C(O[C@H]1[C@@H](O)C=C[C@H]1O)c1c(O)ccc2ccccc12</smiles><smiles>O=C(O[C@H]1C(=O)C(Br)=C[C@@H]1O)c1c(O)ccc2ccccc12</smiles><smiles>Cc1c(-c2ccccc2)oc2c(C(=O)O)cccc2c1=O</smiles><smiles>CCOC(=O)c1oc2cc(O)cc(O)c2c(=O)c1-c1ccc(OC)cc1</smiles>

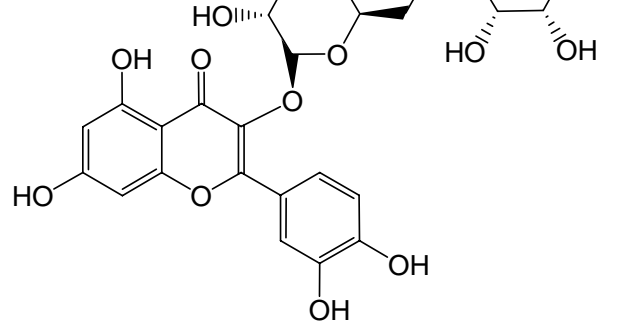<smiles>O=c1ccoc2ccccc12</smiles><smiles>O=c1ccc2ccccc2o1</smiles> 
Figure 3. HSQC experiments indicating specific binding of flavone 1 and alpha-naphthoflavone to apoNCS.

Chemical structures of flavone_1 and $\alpha$-naphthoflavone $\mathbf{2}_{1}$ and the ribbon structures of apoNCS with HSQC data plotted onto them (large ribbon width indicates whether residue's HSQC resonance has been perturbed greater than one standard deviation above the mean).<smiles>O=c1cc(-c2ccccc2)oc2ccccc12</smiles>
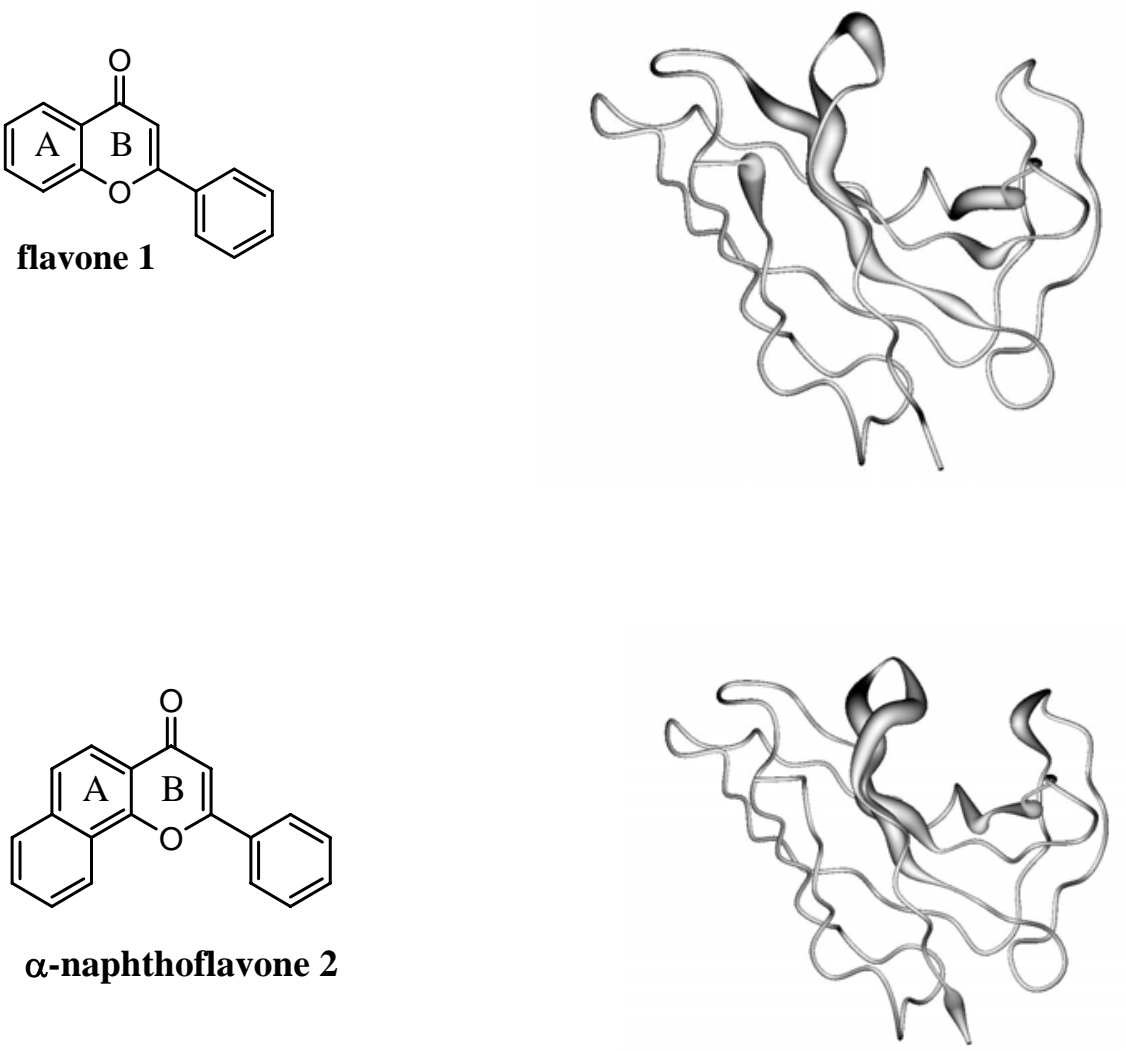

$\alpha$-naphthoflavone 2 
Figure 4. Structures and overlay depictions of ligands 1, 3, and 4 bound to apoNCS.

(a) Neocarzinostatin chromophore (NCS Chrom, 4) in cyan bound to apoNCS (grey); (b) Overlay of NCS Chrom 4 (cyan) and naphthalene analogue 3 (purple) bound to apoNCS (grey); (c) Overlay of NCS Chrom 4 (cyan), naphthalene analogue $\mathbf{3}$ (purple) and flavone 1 (red) bound to apoNCS (grey). (d) Overlay of relative orientations of NCS Chrom 4 (cyan), naphthalene analogue 3 (purple) and flavone 1 (red) in the binding cleft of apoNCS (not shown).

(a)
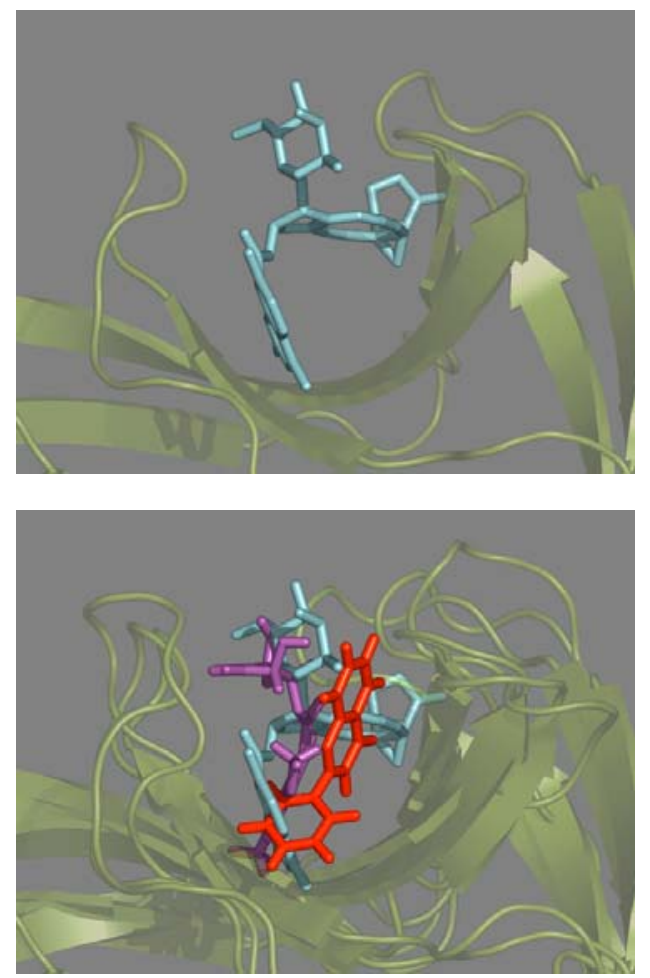

(c) (b)
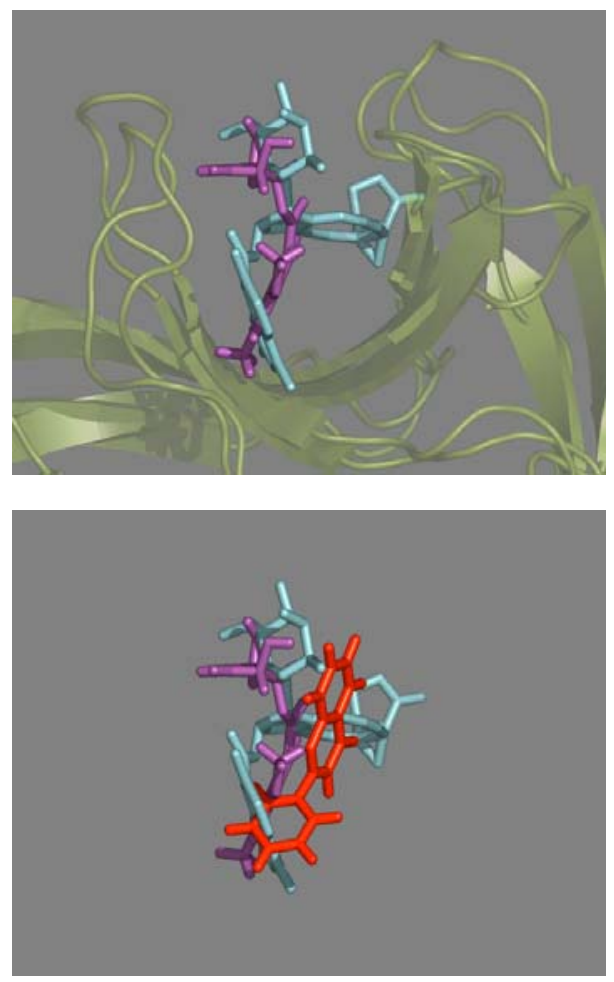

(d) 